\title{
Foucault, Normativity and Critique as a Practice of the Self.
}

\author{
Béatrice Han-Pile \\ Department of Philosophy and Art History \\ University of Essex
}

\begin{abstract}
:
In this paper I distinguish between two main critical questions: 'how possible' questions, which looks for enabling conditions (empirical or transcendental) and raises issues of epistemic normativity; and 'whether permissible' questions relating to conditions of legitimacy and ethical normativity. I examine the interplay of both questions in Foucault's work and argue that this helps us to understand both the function of the historical a priori in the archeological period and the subsequent accusations of crypto-normativity levelled against Foucault by commentators such as Taylor and Habermas. I chart the complex conceptual space available for a defence. After examining several possible replies (in particular deflationary and constructivist), I conclude the most effective option, and the one that fits Foucault's approach best, is to refuse the demand for normative justification as self-defeating and to opt for the cultivation of an appropriate ethical sensibility through an emphasis on critique as a performative practice of the self. I offer in conclusion some thoughts on what such practice may look like for Foucault.
\end{abstract}

KEY WORDS: Foucault; critique; normativity; historical a priori; crypto-normativity; conditions of possibility; freedom; practices of the self.

It may be helpful, in considering the meaning of 'critique' in Foucault's work, to distinguish between two main types of critical questions. Both search for what I shall call 'enabling' conditions, but understand such conditions very differently. First, 'how possible' questions (1). Typically, such questions start from a state of affairs and ask what conditions need to be fulfilled for that state of affairs to be the case, or to be intelligible. This can be done empirically, in which case the answer is likely to be the identification of causally enabling conditions (sets of natural, social, political etc. factors), with no normative consequences: to answer the question is to say what has been the case so that the state of affairs considered could take place. Alternatively, this can be done formally, in which case the answer will most often take the form of conceptual or transcendental conditions. These are conditions of intelligibility and involve a form of epistemic normativity: to answer how possible questions in this way is to describe what must be the case for the state of affairs under consideration to be intelligible, ${ }^{1}$ i.e. to name what I shall call 
epistemically enabling conditions. Second, 'whether possible', in the sense of 'whether permissible', questions (2). Such questions look for ethically enabling conditions which would provide ethical legitimacy for states of affairs the conditions of possibility of which may also be charted in response to the how possible question. 'Whether possible' questions involve issues of ethical normativity: answering them will tell us what ought to be the case if we are to live our lives in the best possible way. Note that these two types of questions can be asked in a metacritical way, i.e. about critique itself as a form of inquiry. Typically this involves asking about the conditions of possibility of ethically normative assessments (asking (1) about (2), i.e. under which epistemically enabling conditions are such and such ethical assessments intelligible), or conversely asking whether certain epistemically enabling conditions can have more ethical legitimacy than others (asking (2) about (1)). This meta-critical dimension is important because both types of meta-inquiry arise within or in relation to Foucault's work.

In what follows, I explore the intertwining of the two types of critical questions in Foucault's work as well as the consequences of such intertwining. Firstly, I suggest that Foucault's archaeological works are best understood as appropriating and rephrasing the Kantian 'how possible' question so as to introduce the notion of 'historical a priori' (itself reinterpreted from Husserl) as a revised answer to this question. I argue that in doing so, Foucault occupies an interesting but ambiguous position because he is both taking up the Kantian inheritance against purely empiricist approaches and turning it against Kant by naturalising the transcendental. Secondly, I suggest that the pluralistic way in which Foucault answered the search for epistemically enabling conditions (the multiplicity of historical a prioris) is one of the main reasons why 'whether possible' questions arose in relation to his work, in ways which could not happen with the original Kantian inquiry. Although he professed neutrality, Foucault often took an ethically normative stance in implicit response to whether possible questions. As it is well known, this gave rise to accusations of crypto-normativity by commentators such as J. Habermas or C. Taylor. I chart the complex conceptual space available for a defence and conclude that the best available option for Foucault to answer challenges about ethical legitimacy is to refuse the demand for external justification and to opt for the cultivation of an appropriate ethical sensitivity through the exercise of critique as a performative practice of the self. I offer a few thoughts on what such practice may look like for Foucault.

\footnotetext{
${ }^{1}$ What Allison (2004) calls 'epistemic conditions', in contra-distinction to causal, psychological or ontological conditions, are a good example of such normatively enabling conditions, with the proviso that Allison's are not concerned with intelligibility in general but with objective knowledge.
} 
Foucault's double-edged answer to 'how possible' questions: archaeology and the historical a priori.

I have argued in previous work (Han: 2002) that Foucault's work can be profitably seen as a reinterpretation of Kant's critical project: like Kant, Foucault is concerned with the search for epistemically enabling conditions. In Kant's case, however, the intention was to provide a universal grounding for knowledge: this lead to the identification of sensory conditions (transcendental Aesthetics) and conceptual conditions (transcendental Analytic) which must both obtain for objective knowledge to be possible. By contrast, Foucault's relation to the Kantian project is complex: on the one hand, he rejects purely causal accounts of knowledge: 'the type of intelligibility that I try to produce cannot be reduced to the projection of a history - a socioeconomical history, say — onto a cultural phenomenon so as to make it appear as the necessary and extrinsic product of that cause' (EW 2: 278). For Kant, the model of such causal accounts was provided by Hume's empirical psychology, which explained knowledge in terms of habitual mechanisms and psychological laws. For Foucault, the target was mainly Marxism, in particular the scientific interpretation defended in France by his former teacher Althusser, according to whom ultimately everything is reducible to 'determination in the last instance by the infrastructure' (Althusser \& Balibar, 1970: 98-99). From this perspective, 'how possible' questions can and must be answered causally only. By contrast, Foucault's refusal to collapse the two dimensions of 'how possible' questions (empirical and transcendental) onto each other was one of the core reasons of his sustained reluctance to adopt a Marxist approach to historical phenomena: throughout his work, he sought to 'determine under which conditions something can become an object for possible knowledge' as opposed to 'finding out the empirical conditions which may at a given time have allowed a general subject to know an object pre-given in the real world' (DEIV: 632, my translation).

Yet although he rejected causal accounts as overly reductive, Foucault also denied the foundationalist ambitions of the Kantian solution. His own answer took the form of various historical a priori identifying the conditions of intelligibility specific to given epochs. Unless these conditions, which he later called conditions of 'acceptability', were satisfied, nothing could count as true or false, nor consequently be a candidate for knowledge. Thus, nothing could be considered as an item of knowledge during the Renaissance unless at least some of its resemblances, relations of sympathy and antipathy and analogies with other items in the same epistemic space had been explored and mapped out. By contrast, during the Classical Age to know something meant to

\footnotetext{
2 (in the lecture 'Was ist Aufklärung' given for the Bulletin de la Société Française de Philosophie in 1978).
} 
analyse it into its simple elements and identify it differentially from other items on the epistemic chart ('tableau'). In Foucault's terms, the historical a priori of the Renaissance was that of the 'Same', and the historical a priori of the Classical Age, that of 'Order', and each during their respective epochs held sway over forms of intelligibility and knowledge. Yet as is clear from such examples, Foucault did not hold the validity of these a priori to be universal, nor their modality to be unequivocally necessary. Although each historical a priori defined binding epistemically enabling conditions at a given time, their scope was limited both temporally and geographically: historical a priori changed. While Foucault notoriously refused to elaborate on the reasons for these epistemic shifts, we may extrapolate as follows: although they are not reducible to empirical practices, historical a priori are dependent on such practices. And when the practices change, so does the relevant historical a priori. Thus in the Birth of the Clinic the changes in clinical practice due to the French revolution resulted in the birth of a new form of medicine, anatomo-pathology, which deeply transformed both the 'medical gaze' and the condition of intelligibility of illnesses: pathologies which had been previously understood according to ideal types and lists of signs were now understood as the symptoms of internal disorders and re-described through a functional analysis of the various parts of the body. Although no practice in particular could be pinpointed as the cause of the change, the historical a priori of medical perception was irreversibly and radically transformed. While Foucault did not use the term, the notion of supervenience seems to describe aptly the relation of each given historical a priori to the dominant practices of the same epoch. According to the standard definition, A set of properties A supervenes upon another set B in case the two sets are notreducible to each other and yet no two things can differ with respect to A properties without also differing with respect to their B properties. In the same way, while no historical a priori is reducible to empirical conditions, if the relevant empirical conditions change, so will the historical a priori.

Thus Foucault's relation to Kant's own interpretation of the 'how possible' question is very ambiguous: on the one hand, he takes up the idea that epistemically enabling conditions are best analysed at a specific level, that of the a priori; on the other, the historical character of such $a$ priori reaffirms the dependency of epistemically enabling conditions on empirical factors. However, and crucially, such dependency, while it can be observed through the analysis of empirical changes, is not reducible to causal relations. Thus Foucault endorses the Kantian idea of epistemic normativity but contests the scope and modality of the Kantian epistemic conditions. So how are we to interpret the overall direction of such a move? As often in such situations, it may largely be a case of aspect-seeing. Foucault's introduction of the historical a priori can certainly be seen as a radical critique of the Kantian project: in this case, that a priori are historical means that 
there is no true a priori in the Kantian sense. This is the line I favoured in previous work, and it is supported by substantial textual evidence (see for example DE IV: 449, 574 and 779). However it now seems to me that a compatibilist reading is also possible: in that case, the variable historical a priori identified by Foucault would be seen as supplementing an invariant governing with genuine universality and necessity all the forms of knowledge that are and may become available to us. What might such an invariant look like? Recall that the later Foucault redefined his approach as an 'analysis of the conditions under which certain relations between subject and object are formed or modified, insofar as they are constitutive of a possible knowledge' (DE IV: 632, my translation and italics). He developed the claim by explaining that any type of knowledge rests on a particular relation between modes of objectification and modes of subjectification. ${ }^{3}$ For him the historical forms taken by such modes are variable: in Greek antiquity knowledge was understood as gnosis and the corresponding form of subjectification was the askesis by which the knowing subject was meant to make himself worthy of what was to be known. The matching form of objectification consisted in the known item being integrated to the knower's ethos and bios in such a way that this person's very comportment became the lived attestation of what he knew (so the courage shown by Laches in battle was the proof that he understood the nature of courage). By contrast, on Foucault's reading of the Cartesian 'turn of the screw' ('tour de spire'), by the $17^{\text {th }}$ century the dominant assumption had become that all that was needed was for the subject's innate rational abilities to be guided by the appropriate method. Correlatively, the dominant form of objectification was representability by such a universal subject of knowledge. These forms of subjectification and objectification are significantly different: yet in all cases, that there should be knowledge tout court required an subjectification/ objectification relation. On this compatibilist reading, then, the historical a priori would be spelling out additional, and weaker, epistemically enabling conditions, which allow us an insight into the specific forms taken by the relation between modes of subjectification and modes of objectification presupposed by all forms of knowledge.

There is more textual evidence in favour of the incompatibilist reading; yet it is quite possible that if Foucault had been able to develop his later investigations into the hermeneutics of subjectivity, he might have more explicitly turned towards the second, compatibilist interpretation. In the absence of any further evidence it is very difficult to adjudicate, although I

\footnotetext{
${ }^{3}$ Respectively: 'what the subject must be, which condition he is subjected to, which status he must have (...) to become the legitimate subject of such or such type of knowledge' and the set of conditions under which 'something has been able to become an object for possible knowledge, the way it could be problematised as an object to know, the kind of carving up process it was subjected to, the part of it that was considered relevant' (ibidem).
} 
now favour the compatibilist reading. ${ }^{4}$ At any rate, whether one reads Foucault's search for epistemically enabling conditions in a compatibilist or incompatibilist manner, an important consequence of his pluralistic perspective on answering 'how possible' questions was to give rise to meta-critical issues of ethical normativity in relation to his own project (in the terms previously used, asking 'whether possible' questions about answers to 'how possible' questions). This couldn't have happened with Kant: from the latter's perspective, it would have made no sense to ask whether our set of epistemically enabling conditions is more legitimate than another because there is no alternative standpoint for us from which to ask that question intelligibly. But in Foucault's case the very plurality of historical a priori invites by itself normative comparisons: is our historical a priori better than that of the Renaissance, or of the Classical age? Or, as was often asked of him, were Greek 'problematisations' preferable to ours? ${ }^{5}$

In order to deflect such meta-critical questions, Foucault adopted what we may call the principle of archaeological neutrality. This principle was deployed at two levels: firstly, it is a form of ethical neutrality. Foucault refused to make any claims about the historical a priori or practices of a particular epoch being 'better' than others, in the sense of being ethically preferable. As the detached tone of the History of Madness' description of Dr Pomme's treatment for what we would now call hysteria shows, Foucault was concerned with bringing out the relative alienness of past conditions of intelligibility and forms of knowledge without interference from value judgments. Secondly, archaeological neutrality is also a principle of epistemic neutrality: we have to suspend our standards of evidence and refrain from judgments about past forms of knowledge being more or less true than ours. So when looking at the relation between Buffon and Aldrovandi's work in The Order of Things, Foucault is only concerned with showing the shift in epistemically enabling conditions from the Renaissance to the Classical Age: it is of no import to him whether natural history is more correct than Aldrovandi's collections of legenda (things to read). The main ground for applying the principle of archaeological neutrality is that otherwise our contemporary (or personal) ethical commitments would distort the phenomena under study (e.g.: the past conditions of intelligibility). Thus normative neutrality is a requirement for hermeneutic success: it is

\footnotetext{
${ }^{4}$ Thus I agree with Amy Allen (2008) that 'Foucault's work is best understood as an immanent rather than a total critique of the Kantian (...) project' (p. 24; see also p. 28). However unlike Allen I do not think that Foucault sees Kant's Anthropology as harmonious with the first Critique but rather as in dialectical tension with latter on the key issue of the relation between the empirical and the transcendental.

${ }^{5}$ One may worry that since for Foucault it is impossible to revert to a previous historical a priori the comparison would be purely academic. However there is an important practical point to it, which is that it enables us to see whether some good (or at least, better) aspects of previous épistémès may survive as marginal practices that could be reinterpreted in the light of the current historical a priori, and perhaps even contribute to an epistemic change (although this would only be visible retrospectively). It is in this way that Foucault reads friendship, for example.
} 
intended to prevent us from reading back epistemic or ethical standards into the objects that we study, so that the relevant epistemically enabling conditions can appear in a purer form.

Yet there are reasons to worry that archaeological neutrality may only be a fiction (just like the phenomenological ideal of a pure description). Foucault is usually careful to avoid directly evaluative terms but it is clear that he values difference over identity: 'do not ask me to remain the same' (AK: 17), he famously said in the introduction to the Archaeology of Knowledge. Other statements make his implicit normative stance more explicit, such as this one: 'it's a matter of constructing cultural forms. (...) We must fight against the impoverishment of the relational fabric. We must secure recognition for relations of provisional coexistence, adoption' (EW1: 1578, my italics, translation modified). And in a well-known passage of the introduction to the Use of Pleasures Foucault explicitly states his preference for emancipatory transformation over stagnation: 'It was a philosophical exercise. The object was to learn to what extent the effort to think one's own history can free thought from what it silently thinks, and so enable it to think differently' (UP : 9 ; see also DEIV: 42, EW1: 315). It is clear from these quotes that Foucault did not practice archaeological neutrality with respect to the relation between difference and identity, change and stagnation, and most of all freedom. In a similar spirit, Foucault held that Greek forms of problematisation, while not perfect, were closer to being practices of freedom than our own. Thus Foucault's implicit response to the meta-critical issues arising from his epistemic pluralism was to express a set of normative commitments focused by the need to preserve and enhance personal freedom. Yet the fact that he did not provide any explicit justification for holding freedom as an ethical criterion is doubly problematic: historically, it generated a set of accusations of crypto-normativity; theoretically, it leaves his normative commitments vulnerable to further objections about issues of ethical legitimacy. It is to these accusations and objections, and so to the play of the second type of critical question in his work, that I shall now turn.

'Whether possible' questions in Foucault's later work: objections, first replies and further difficulties.

Foucault did not offer any justification for his prioritisation of freedom over other values. For some of his critics, the problem is not simply that he did not, but rather that he could not offer such justification, on pain of an internal contradiction between his criticism of the conception of reason put forward by the Enlightenment on the one hand, and the need to justify his implicit normative claims on the other. Generally put, the thought is that by criticising the first, Foucault would have removed the one possible ground for the second. In Habermas' terms, 'critique 
becomes total: it turns against reason as the foundation of its own analysis'. ${ }^{6}$ Thus Foucault is confronted with an unsavoury alternative: either renounce his criticism of rationality or give up on his normative claims. As the danger is ethical scepticism, it is perhaps not surprising that his critics faced him with all three sides of the Agrippan trilemma, namely: (a) infinite regress, in which case a justification is offered but it raises further 'why' questions; (b) circularity, when a justification is offered but assumes what it seeks to prove and thus begs the question; and finally (c) dogmatism, which offers no justification but at the cost of the position seeming arbitrary and unconvincing. ${ }^{7}$ Although I shall refrain here for lack of space, Taylor's, Fraser's and Habermas' criticisms can be analysed as upholding various sides of the trilemma. Furthermore, Foucault's ethically normative commitments are vulnerable to two additional criticisms. First, the claim that the ethical legitimacy of a negative normative stance should be conditional on the prescription of alternative solutions as otherwise the normative insights, even if they were theoretically justified, would be pragmatically invalidated by their adverse consequences. Second, one may argue that the very possibility of having an ethically normative stance is conditional on having a conception of an alternative model. The thought here is that unless one has a contrasting, positive standpoint from which to normatively assess a bad situation, such assessment is not possible in the first place (regardless of how its principles or content would be justified) because there is no perspective from which it could be made: and as it is well known, Foucault was wary of utopias and did not put forward a model of the good. This second difficulty is a radicalisation of the so-called 'problem of the criterion' which does not question the internal justification of the criterion but what makes it possible to have a criterion in the first place. In the terms used above, this last worry is metacritical, but in the reverse direction to the one examined in relation to archaeology: rather than inquiring into the ethical legitimacy of epistemically enabling conditions, it asks about the epistemically enabling conditions required for ethical answers to 'whether possible' questions.

Due to space constraints, I shall now suggest brief replies to the last two objections before attending to the first in more detail. With respect to the meta-critical objection, the best option, it seems to me, is to accept the need for a contrast between better and worse states of affairs as a necessary condition for adopting an ethically normative stance, but to deny that such contrast requires a positive conception of the good. Having a pluralistic and hierarchical understanding of the bad allows for sufficient contrast to assess the comparative merits of various states of affairs. Thus there is no need for Foucault to put forward a full blown, positive model of freedom to be

\footnotetext{
6 'Myth and Enlightenment': 21-22.

${ }^{7}$ Sextus Empiricus, Outlines of Scepticism, CUP: 2000, p. 67-69. For an exploration of such dilemma, see for ex. P. Franks, All or Nothing, Harvard UP: 2005.
} 
able to claim that Greek forms of power were more amenable to the fostering of individual freedom than disciplinary power. Even though by Foucault's own count Greek forms of life were not ideal, the contrast between the effects of the ancient spiritual practices of the self on the one hand, and those of the subjugation techniques characteristic of disciplinary power, on the other, is sufficient to allow for his relative prioritisation of Greek forms of problematisation. Thus it is enough to deflect the meta-critical objection that Foucault should be construed, in F. Freyenhagen's term, as an epistemic and meta-ethical negativist (in other words, as committed to the view a) that we can know the bad without knowing the (ideal) good and b) that knowledge of he bad suffices for normative judgements about comparative merits). ${ }^{8}$

Foucault explicitly addressed the second objection by denying the requirement for a link between normative evaluation on the one hand, and prescription on the other (see DE IV : 32). His task, as he understands it, is to reveal the hidden theoretical assumptions and historical contingency of the problematisations that govern our understanding of ourselves and of the world: to offer ready-made solutions would be to act as a 'prophet' and to infantilise his audience (DE IV: 537; see also 93). Note, however, that this rejection of prescriptivity presupposes precisely the sort of ethical commitment which is still in need of justification, namely a normative view of human agency which prioritises the preservation and maximisation of freedom. Foucault is explicit about such commitment: '[critique] is seeking to give new impetus, as far and wide as possible, to the never ending work of freedom (EW1 : 316, translation modified) Thus his answer to the pragmatic objection takes us back to the issues raised in relation to the first objection, which I shall now attend to.

Foucault's response consists in denouncing what he called the 'blackmail of the Enlightenment', namely the thought that in order to justify rejecting the standards of the Enlightenment, one would have to ground one's position precisely by using the sort of universal concepts or arguments rejected. For him this objection, although it presents itself as a form of immanent critique, presupposes an external standard, namely the claim that only universal and objective reasons are valid: and this standard is one which he explicitly rejects. Much of the thrust of his work lies in criticising the claim that rationality should be understood univocally and ahistorically. Genealogy reveals that requirements or concerns which are presented as universally justified are often the contingent result of politically motivated changes in social practices and processes: in Discipline and Punish the humanitarian discourses of the $18^{\text {th }}$ century are shown to be born from (and to mask) the same social and political imperatives that shaped the reformation

\footnotetext{
${ }^{8}$ See. F Freyenhagen (2013). I am grateful to him for clarification on this issue.
} 
of the prison system and led to further loss of individual freedom. More generally, Foucault sought to provide a 'history of all the ramifications and the bifurcations, a contingent history of reason', rejecting any unifying narrative. One may add that it does not follow from the rejection of absolute grounds that no grounds at all can be offered. As in the case of Nietzsche's views on value, there is no logical entailment from perspectivism to total relativism. The 'blackmail of the Enlightenment' rests on an implicit 'all or nothing' logic which seeks absolute rational justification and, in its absence, threatens with a collapse into absolute relativism. Yet such logic, far from being a rampart against Foucault's alleged nihilism, is in itself nihilistic: to hold this 'all or nothing' view is precisely to open the door to the sort of nihilism of despair which is held out as a threat in case of the collapse of universal grounds by removing the possibility for any other kind of ethical justification, thus generating an impossible demand.

It would be unwise, however, to take Foucault's response as the last word on the matter: for even if we give up on external, universal reasons, surely there must be some internal and relative grounds for the prioritisation of particular values? In the absence of such internal reasons arbitrariness would threaten. And yet Foucault did not offer even relative justifications for his normative stance, at least not in any explicit form. Thus the problem of the criterion arises anew, albeit in a different form: what relative grounds can Foucault have for holding up the preservation and maximisation of freedom as a normative standard? I shall consider three possible replies: deflationary, conceptual and alternative. ${ }^{9}$

\footnotetext{
${ }^{9}$ Both Allen (2008) and Oksala (2005) raise the question of justification in the context of Foucault's later work (in particular on p. 42 sq. and 169/178sq. respectively). However in my view neither provides a definitive answer to it. Allen makes the valid point that 'it's a mistake to think that the only available options are being either wholly inside or wholly outside of the épistémè in question' (43). However this only establishes the possibility of having a critical standpoint, not the validity of the proferred critique, and thus is an answer to the third criticism above (the problem of the criterion), not to the question of justification. In Allen's terms, 'taking up a critical perspective on this épistémè is possible, though that critique is necessarily grounded in that épistémè'(ibidem): it is precisely whether such 'grounding' can be legitimately offered which is at stake here. Oksala offers two answers: the first consists in emphasising Foucault's rejection of prescriptive ethics $(169,180)$. However this leaves the issue untouched as for his critics Foucault's own normative commits would remain in need of justification regardless of whether he wants to act as a 'prophet' or not. Oksala's second answer is both more promising and more ambiguous. It consists in saying that 'the underlying values and normative criteria are unarticulated, not because the philosopher should not provide them for us, but because he or she cannot provide them' (170). Oksala develops a conception of critique as 'philosophy lived', capable of displaying ethical values through the philosopher's comportment, but not of articulating them. Although it is not framed by the interplay of the two kinds of critical questions, this conception resonates with the one I argue for below. However it is unclear from Oksala's formulation whether the impossibility of a grounding articulation should be seen as a vice the ethicist must perforce make do with, or as a virtue: in other words, whether it is the case that the philosopher should provide a normative framework but is empirically defeated by the nature of her ethical commitments (in which case 'lived philosophy' can only be a fall-back and possibly inferior option), or whether one should give up on the demand for the articulation of a normative framework altogether. In the
} 


\section{Further replies}

The deflationary route consists in recognising that since there is no Archimedean standpoint from which one could pronounce the standards of a culture better than those of another, all we can do is construct genealogies which show how we arrived at what we think now. From this perspective, one should refuse the idea that even relative grounds need to be offered in favour of spelling out a multiplicity of existential options and relying on the contrast to broaden our horizon of thought. This deflationary position is not dissimilar to Raymond Geuss', or to Bernard Williams' 'relativism of distance', i.e. the idea that while we shall never understand past practices in the way they would have been understood by the (now dead) cultures who used them, such practices are still worth analysing for what they have to tell us a contrario about ourselves. This chimes with several of Foucault's claims, in particular the idea that all he ever wrote were 'fictions' and his later emphasis on doing a 'history of the present' whose reconstructions of the past are primarily motivated by the concern to understand and transform the present. The aim is to foster the awareness that our own practices and forms of intelligibility are not the only possible ones, so that alternative paths can be considered and explored: 'contributing to make certain things change in the ways we perceive and do, taking part in this difficult displacement of forms of sensibility and thresholds of tolerance - I don't feel in a position to do much more' (DE IV: 31, my translation). However, as in the case of archaeological neutrality it is not clear that this deflationary stance is the one that Foucault genuinely adopted in practice. For he is not just a pluralist about existential options: he thinks that some practices, such as the cultivation of friendship and the development of practices of the self, are better than others, such as (for example) confession or disciplinary mechanisms. Thus while the deflationary stance is theoretically attractive and captures some of the aspects of Foucault's work, there are reasons to doubt that it was consistently applied (if at all). I shall now consider the two other possibilities: a conceptual argument for freedom, and the alternative ethical sensitivity line.

As argued above, Foucault's constructivism does not per se commit him to total relativism. One possibility for the justification for his normative commitment to the preservation and maximisation of freedom would be to derive it from forms of practical reasoning, or from the concept of agency itself. While he did not explicitly offer such a derivation, some of Foucault's pronouncements about freedom may be interpreted in this direction, in particular this one: 
'freedom is the ontological condition of ethics. But ethics is the reflective form of freedom' (EW1: 284, translation modified). The thought that freedom is the 'ontological condition' of ethics may be understood in the following, Kantian (or more recently, Korsgaardian) way, itself intuitively suggested by the way in which this statement echoes Kant's claim in the Second Critique according to which freedom is the ratio essendi of the moral law, and the moral law, the ratio cognoscendi of freedom. For Kant it is a condition of possibility on agency that we should (explicitly or not) consider ourselves as free. This is true regardless of whether one is a compatibilist of an incompatibilist about the objective relations between human freedom and natural laws, for unless we act 'under the idea of freedom', we cannot understand ourselves as responsible agents. Since no ethics is possible without agents, such reliance on the idea of freedom is the condition of possibility of ethics: being an agent just means understanding oneself to exercise one's freedom when one acts, and having an interest in preserving and maximising such exercise. Thus freedom is indeed the ontological condition of possibility of ethics, as Foucault says, and a justification for its prioritisation can be derived from the very concept of an agent.

However this argument is not without difficulties. For one thing, although it goes a long way towards justifying the importance of freedom for Foucault, it does not offer an ethical justification. What the conceptual argument highlights is a matter of epistemic necessity: unless we take ourselves to be free agents, we cannot be agents at all. But showing that something has to be the case, namely that agents have to conceive of themselves as free and to take an interest in the preservation of their freedom, does not ground the claim that freedom has any intrinsic ethical value. All that it establishes is that it is conceptually necessary for agents to presuppose that they are free, and to value their freedom. Additionally, once put in the context of Foucault's work the argument becomes problematic because of its uncritical reliance on the concept of a rational agent. Such a concept is implicitly taken (in Kant and Korsgaard at least) to be a-historical and universal. Yet part of the thrust of Foucault's genealogical critique is to deny this alleged a-historicity and universality by showing that the characterisation of agency in terms of freedom and autonomy dates back to the Enlightenment. Thus for early Christians freedom featured very low on the agential picture: to be an agent meant to love God with all one's heart, to find ways of opening one's mind to his wisdom, and to obey His will in everything. Augustine warns specifically against understanding agency in terms of freedom and self-reliance: 'for, cursed is the man who trusteth in himself' (Enchiridion: 132), a warning which is echoed by the Confessions (179): 'pride and a kind of ruinous self-sufficiency are the informing principles [of vice]'. From Foucault's perspective, then, availing oneself to the concept of an autonomous agent as if it were timeless is a naiveté which is not acceptable for the genealogist. Thus the second horn of the Agrippan 
dilemma (circularity) threatens again: the conceptual argument presupposes what it is trying to show because it relies on a contingent conception of agency which has the existence and preservation of freedom as its inbuilt presupposition. One may point out, by way of further reply, that although it has a date of birth and is relative to a specific period of human history, this conception of agency may well be the only one available to us now. That it has historically datable origins does not mean that there are any viable alternatives for us: we cannot regress to prior conceptions of agency. The necessity involved in the conceptual argument from freedom may not be absolute and conceptual but relative and historical, but it still remains a necessity for us. This may well be the case: yet even so the first problem would remain, namely that the justification offered is not of an ethical nature, and thus does not really answer the search for relative ethical grounds. Consequently, I shall now turn to the last option on the table, the alternative ethical sensitivity route.

This strategy consists in denying, à la Bernard Williams, that any justification in the form of (even relative) reasons articulated as sets of propositions linked by various inferences is needed at all, on the grounds that this gets the ethical phenomenology wrong. The underlying idea is that the source of normativity is not a code, or a set of arguments, but the ethical sensitivity to particular situations which we acquire from familiarity with our culture and practices. Such sensitivity is the ground of our ethical life and pre-empts the need for justification. It can be developed in such a way that we become masters at identifying the salient ethical features of a situation and at developing the appropriate response. From this perspective, the demand even for a relative ground for normativity remains too Kantian and too deontological in nature: we cannot, and should not, try to justify our ethical beliefs from the ground up. And if challenged, we can only provide justifications to those for whom our ethical considerations already have some force: in Bernard Williams' terms, there are no functional external reasons (i.e. reasons that would hold for anyone, regardless of their relation to that person's motivational set) because such reasons would exert no traction on us. To others, we cannot offer justifications, but "merely" try to make them sensitive them to the normative orientation by way of examples, narratives and the like.

Foucault sees the task of critique exactly in this way: it is not meant to provide justifications but to re-shape our ethical sensitivity by fostering better self-understanding and by transforming our practices. Far from being an intellectual enterprise or a 'permanent body of knowledge that is accumulating' (EW1: 319) and would seek to understand its object from a detached, third person standpoint, Foucault's 'critical ontology of ourselves' is a 'philosophical ethos', 'work carried out by ourselves on ourselves as free beings' (EW1: 316). This critical work has two intertwined dimensions: firstly, it involves an increase of self-awareness through which we come to experience 
more clearly that the ways in which we think, perceive and normatively respond to the solicitations of our world are rooted in a particular cultural inheritance (in the present case, the Aufklärung). Secondly, and correlatively, this increased self-awareness allows us to stretch the limits of that experience so as to seeks ways of transforming ourselves and - should the movement of individual self-transformation should gain enough societal momentum — of finding institutional and cultural paths to reshape the current paradigm. Promoting this kind of awareness was, for example, one of the main functions of Foucault's critique of the problematisations typical of psychoanalysis: it contributed to genuine social change through the displacement of the heterohomosexual model in favour of a third term, 'gay', and the introduction of new institutional forms such as the French gay marriage (PACS). Thus Foucault's critical ontology of ourselves is not a theory: it is 'an attitude, an ethos, a philosophical life' (EW1: 319, my italics). It is a matter of developing our ethical sensitivity to our world, and of finding ways of transforming some of the aspects of this world by experiencing in ourselves new, or at least significantly different, possibilities for modes of life.

My sense is that the ethical sensitivity route is the most congenial to Foucault's views. It captures his conception of the task of critique and more generally chimes with his sympathy for virtue ethics and his implicit rejection of deontological approaches in the introduction to the Use of Pleasures..$^{10}$ However, Foucault's approach does not map exactly onto Williams'. Recall that the latter held the view that ethical reflection is potentially deleterious because it tends to destroy our thick ethical concepts (such as shame, courage, etc.) and thus may inhibit or even destroy an individual's rooting in their native ethical world: it is adverse to the smooth, unreflective functioning of our ethical sensitivity. Yet as we have seen, Foucault greatly values ethical reflection: he sees it as the very movement of freedom. He considers the reflective asking of critical questions as one of the main ways through which the stretching of our normative framework may be facilitated, so long as the function of such questioning is not seen as asking about the ground of normative commitment itself and inviting impossible external justifications, but as highlighting internally problematic areas so that we can transform our practices accordingly. And conversely, engaging in the critical clarification of the problematisations which shape our ways of understanding the world and ourselves in itself validates the debate because it presupposes that we share the same ethical outlook as other debaters.

Note that one important consequence of Foucault's views on the value of critical reflection is that they allow him to resist the implicit conservatism which may threaten Williams' position. For

\footnotetext{
${ }^{10}$ See Han-Pile (2002), part III chapter 1.
} 
without critical reflection, the ethical sensitivity route has a tendency to preserve the ethical status quo by encouraging individuals to be and remain harmoniously attuned to their world. This, in turn, makes it difficult to see why one should resist some of the existing practices rather than acting in their light. By contrast, Foucault's valorisation of the asking of critical questions, joined with his emphasis on the importance of self-awareness in grasping the role of the problematisations that shape our self-understanding, allows him to carve a space for possible resistance to existing practices of domination. Admittedly, this may generate the converse risk to conservatism, namely alienation, if reflection gets radically in the way of an individual's sense of belonging to their world. I shall return to this point in relation to critique as a practice of the self in my concluding remarks. For now, though, we can further note that Foucault's interpretation of our present times introduces an interesting twist and affords us with the contingent possibility of a convergence between his position and Williams. For according to the Foucault, the ethos of the enlightenment is characterised by the exercise of critical reflection: 'the thread which may connect us wit hthe Enlightenment is not faithfulness to doctrinal elements but rather the permanent reactivation of an attitude - i.e. a philosophical ethos that could be characterised as a permanent critique of our historical being' (EW1: 312, translation modified, my italics; see also 316). If this is true, then exercising critical reflection just is acting in the light of the current ethos.

\section{Conclusion: some remarks on critique as a practice of the self}

We are now in a position to realise that the introduction of the historical a priori(s) is not just Foucault's ambiguous answer to 'how possible' questions: perhaps less visibly, but no less importantly, it is a privileged way for us to get traction on how best to understand and answer 'whether possible' questions. As we saw, for Foucault the main function of critique is not to provide justifications but to foster a better understanding of the problematisations that govern our understanding of ourselves and of the world, with the hope that this will result in higher forms of self-awareness and open up a space for personal and social change. What this means, however, is that asking and answering 'how possible' questions has in itself an ethical import: by opening up a space through which the forms of intelligibility which govern us become more visible, questions about epistemically enabling conditions help us get a grip on how best to understand and answer 'whether possible' questions about ethical legitimacy. Thus as one might expect given his views on spirituality as self-understanding and self-transformation, Foucault takes the epistemic aspects of his critique to have direct ethical and practical implications, both societal and individual: '[philosophical discourse] is entitled to explore what might be changed, in its own thought, through the practice of a knowledge that is foreign to it. The 'essay' — which should be 
understood as the assay or test by which, in the game of truth, one undergoes change (...) - is the living substance of philosophy, at least if we assume that it still is what it was in times past, i.e. an "ascesis", an exercise of oneself in the activity of thought' (HS1: 9). The two dimensions of critique, which I had separated for the purpose of analysis, are thus reflexively intertwined and form, in Foucault's work, part and parcel of a single endeavour.

I shall now offer some concluding remarks about how Foucault himself problematised the notion of freedom at the level of the individual. For him, freedom is best understood as the reflective internalisation of the reflexive, dual movement of critique: in other words, critique as a practice of the self. It consists in asking (and answering) 'how possible' and 'whether possible' questions in relation to oneself, with a view to being in a better position to change that self. As for Kierkegaard, selfhood is not a given for Foucault: it is a task, and the function of critique as a practice of the self is to allow us to carry out that task in a partly performative manner. As it is well known, the structure of self-consciousness is such that the movement of reflection is enough on its own to transform its contents. Thus the very asking of critical questions about the sort of self we are, prior to any answer being found or given, has in itself a transformative effect on our self-relation: it creates an internal distance, a space of 'play' (the French 'jeu' as both play and loosening up). The shape of that space is not fixed but changes with our understanding of such questions and the answers we give them (and the further questions that arise from the answers). Inasmuch as possible, critique as a practice of the self allows individuals to look at the conditions of possibility of their own self-understanding: this is a task which cannot be carried out completely because the tools to be analysed are the ones used for the analysis, but as we have seen, contrast with previous historical a priori helps us become more aware of the forms of problematisation and the practices that govern us. Thus critique as a practice of the self reveals itself as the contemporary form taken by the Greek epimeleia heautou (care of the self). It combines the reflective ethos of the Enlightenment with an attempt to revive what has become a marginal practice, namely the antique conception of spirituality as a process of self-transformation through self-examination: 'in its critical aspect (...) philosophy is that which calls into question domination at every level and in every form in which it exists (...). To a certain extent this critical function of philosophy derives from the Socratic injunction: 'take care of yourself, i.e. 'make freedom your foundation, through the mastery of yourself' (EW1: 300-1).

Importantly, this form of critique does not seek to foster identification with a set of core features or desires, as is often the case with Frankfurtian inheritors: the point is not to identify wholeheartedly with oneself, let alone to find a repressed 'true self. This is largely the reason why Foucault rejects psychological conceptions of authenticity, and the ground of his opposition to 
Sartre on this issue. It is not a question either of forming a new 'practical identity' which would regulate our comportment in a consistent way. By contrast, critique as a practice of the self is an exercise in self-displacement, self-estrangement even: one must seek to 'get free of oneself' (HS1: 8). Rather than an attempt to foster self-identification and self-acceptance, critique is perhaps best understood as an internalisation of what Nietzsche calls in the Gay Science 'stellar friendship': 'we were friends, and have become strangers to each other. (...) We are two ships, each of which has its own goal and course. (...) Perhaps we shall never see one another again, or perhaps we may meet again but fail to recognise one another: our exposure to different seas and suns has altered us! That we had to become strangers to one another is the law above us - by the same token (...) the memory of former friendship [should become] more sacred' (GS §279). Analogically, through the exercise of critique as a practice of the self, one has to be both a friend and a stranger to oneself: to retain enough friendship to one's former self that it is not simply discarded, and yet to be able to see it as strange and so to experience oneself as another. Distance, not proximity, the ability to 'look down on oneself from above' (HS1: 11), and the clarity of vision this procures, are essential to such a self-relation.

This repeated emphasis on self-dehiscence, however, raises a threat which I mentioned earlier, namely that of alienation. In its most radical form, Foucault's conception of critique as a practice of the self would prevent identification with any aspect of the self and most likely result in a personality disorder. Perhaps the best way to deflect this threat is to borrow, again, from Nietzsche and to consider that our self-relation through the lens of the acquisition of 'brief habits' (GS : 295; see also GS: 237). By contrast with "enduring' habits, which ossify the self and prevent transformation (and even the desire for transformation arising), brief habits allow for enough continuity that integrity of the self is preserved, but are changeable enough (and importantly, understood as changeable by the individual) to allow for the sort of self-distance sought by Foucault. They also allow for a non-traumatic transition from one form of self-experience to another: we can part from our older self 'as if we had reason to be grateful to each other as we shook hands to say farewell. Even then something new is waiting at the door, along with my faith — this indestructible fool and sage! — that this new discovery will be just right' (GS: 237). From this perspective, each new book, each essay as a transformation of the self, may be seen as the creation of a temporary habitual relation to the self, with the reflective knowledge that this relation is temporary and the relative self-distance and continuity that come with such knowledge. Considered in this way, critique as a practice of the self remains a delicate exercise in self-displacement, but perhaps not an impossibility. 
As a final note, critique as a practice of the self is an infinite task. It is a form of hermeneutic of the self because each new layer of understanding, each change induced by the asking of 'how possible' or 'whether possible' questions transforms the ground of our self-understanding and calls for further questions which in turn will foster further ground shifting. Yet crucially, from Foucault's perspective this critical hermeneutic of the self differs significantly from the original model of the hermeneutic of the self, namely the Christian model, because there is no hidden, endlessly receding, guilty content to ferret out and confess. There is only the relative movement of freedom's reflective self-displacement: in Foucault's words, 'the theoretical and practical experience we have of our limits, and of the possibility of moving beyond them, is always limited, determined, and thus to be undergone again (EW1 : 316-7, translation modified). 
Bibliography:

NB: this is in addition to the general bibliography/abbreviations listed for this particular edition of Continental Review.

Allen, Amy, The Politics of Our Selves: Power, Autonomy and Gender in Contemporary Critical Theory, NY: Columbia UP, 2008.

Allison, Henry, Transcendental Idealism: A Defense, Yale: Yale University Press, 2004.

Althusser, L and Balibar, E, Reading Capital, London: New Left, 1970.

Augustine, Aurelius, Enchiridion, Gateway Editions, 1996.

- Confessions, London: Penguin Classics, 2002.

Freyenhagen, Fabian, Adorno's Practical Philosophy: Living less Wrongly, CUP: 2013.

Han-Pile, Béatrice, Foucault's Critical Project: Between the Transcendental and the Historical, Stanford: Stanford UP, 2002.

Nietzsche, Friedrich, Gay Science, (transl. : Walter Kaufmann), NY: Random House, 1991. 